\title{
Research on the Land-Saving Measures for Tramcar Depots
}

\author{
Dong Shu* \\ China Railway Siyuan Survey and Design Group Co. , Ltd. , Wuhan, China \\ * Corresponding author: 895246261@qq.com
}

Key Words: Tramcar; Depots; Land-Saving Measures

ABSTRACT: In light of the increasingly tense urban construction land, this paper offers an indepth research on the land-saving measures for the tramcar depots and puts forward the related suggestions with a view to fulfilling the target of saving land resources and building conservationoriented tramcar depots.

\section{The Basic Forms for the General Layout of Tramcar depots}

To reduce the size of the tramcar depots, the centralized layout is usually applied to the workshop buildings in accordance with the repair program and system of tramcar. Considering the different functions of storehouses, the workshop repair, medium and occasional repair system, airconditioner maintenance room, bogie maintenance room, pantograph maintenance room and door and window maintenance room are combined into the maintenance station; weekly and three-month inspection station and inspection station are combined into application station; the parking garage can be independently set. According to the positional relationship between the maintenance station, application station and parking garage of tramcar depots, its general layout includes traverse arrangement, longitudinal arrangement and composite arrangement ${ }^{[1-3]}$.

\section{Land-Saving Measures for Tramcar Depots}

\section{Overall Planning and Implementation by Stages}

To control the total quantity of the construction scale of the tramcar system project and maintain the project scale, the standard integrity and the orderly development, the design period of the construction project is divided into the preliminary stage, short term and long term by taking the year of project completion and available transportation as the base year. The preliminary stage includes the first three year after the project completion, the short-term refers to the first ten years and the longterm encompasses the first 25 years ${ }^{[4]}$.

As the logistic base ensuring the ordinary operation of the $100 \%$ low-floor tramcar system, the depots should set a scale for the preliminary stage according to the short-term demands and reserve in line with the long-term planning on the basis of the function and process requirements so as to reduce the investment at the preliminary stage ${ }^{[5]}$. Therefore, it is of great importance to implement by stage in the design of the general layout of depots. Considering the practical design experience of Huandao Depots in Foshan and Shushan Depots in Suzhou, the following suggestions are proposed: (1) Reasonably control the scale of short-term design. In the process of determining the scale of the depots design, it is of prime importance to take into consideration the development of the manufacturing and maintenance technology the tramcar, reasonably determine the examine and repair cycle, time and unbalanced coefficient as well as other design objectives so as to enhance the utilization rate, reduce the design scale and project investment by following the assembly line work for processing design.

(2) Consider the net for long-term planning. For the difference between the characteristics of tramcar system and subway system, the automobile could be used for the repair of the tramcar. For this reason, the sharing of the tramcar system resources is more convenient. Therefore, the layout and scale of the tramcar depots should undergo overall and coordinated consideration on the basis of the regional tramcar network planning. The line depots should be built first by taking into account the workload of the maintenance of the follow-up line vehicles with appropriate land reserved for the long-term development. Meanwhile, it is advisable to avoid the repeated construction of the maintenance functions of the follow-up depots so as to reduce the total area of the net depots. 


\section{Optimize the Combination Mode of Plants}

On the basis of the operation experience of the Tramcar Line 1 in the hi-tech zone in Suzhou, it is advisable to combine the inspection station and parking garage in the tramcar depots into the parking train examination shop; in which, the inspection platform and parking platform are subject to collinear arrangement. If the 4 platform-through type is taken into account, it is suggested to set 3 platforms for inspection and 1 platform for parking in each line. As shown in Figure 1, such arrangement could reduce the shunting frequency in the car depots, enhance the working performance, decrease the amount of turnout as well as the floor area of the depots ${ }^{[6]}$.

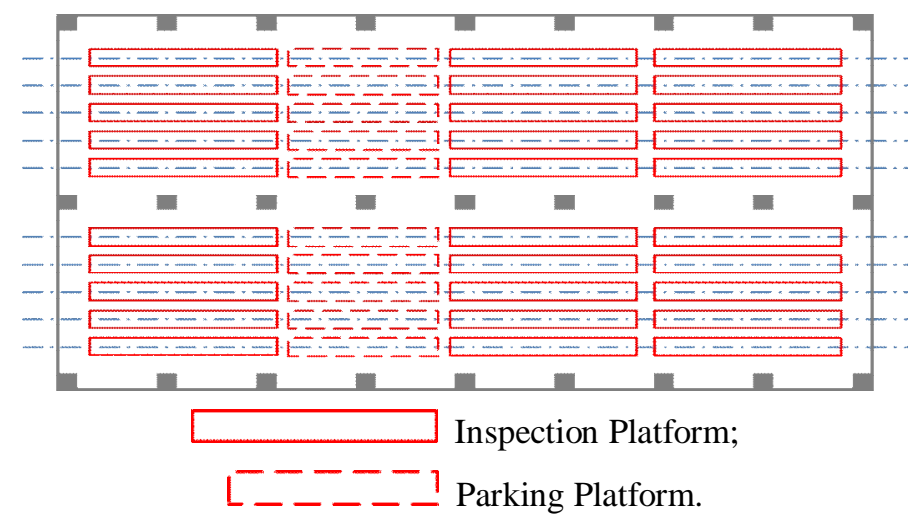

Figure 1. The Sketch Map for the Plane Layout of Parking and Inspection Station

The parking and inspection station and weekly and three-month inspection station could be further combined into the application station. As a result, a pattern featuring the maintenance station and application station with the supplementation of the rooms for production and living will be formed, as evidenced in Figure 2.

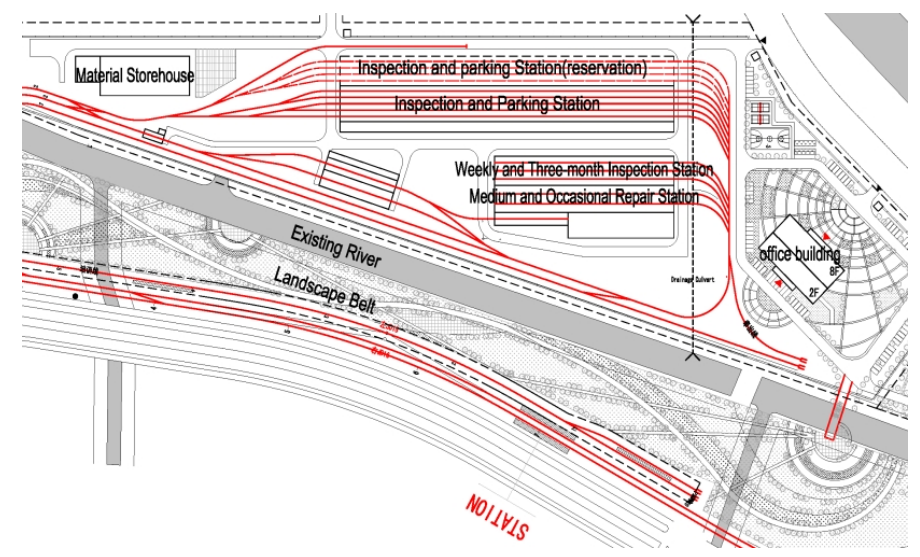

Figure 2. An Example of the Optimized General Layout of Tramcar Depots

\section{Realize the Comprehensive Utilization of Land on the Basis of the Surrounding Planning of the Sites}

As the place for the operation and maintenance of all the vehicles, the depots usually takes up a large area and is located in the city outskirts. When the tramcar is open to traffic, it has very convenient transportation with great potential for property development. On the basis of collecting and integrating the abundant relevant development cases at home and abroad and in accordance with the spatial relationship between the stabling yard and ground, the mode for the comprehensive utilization of the depots land could be summarized as follows:

(1) Carpet Model

According to this model, the tramcar depots is horizontally located on the ground. The various functional plants storehouses are integrated into a platform as the land for the development and construction of properties. The property development will be conducted above the platform. The platform and surrounding municipal administration paths are connected through the terrain and ramps and the comprehensive depots combined with the subway stations for upside-down arrangement; due to seamless flat-layer connection, people could enter into the superstructure above the depots through the tramcar station. 


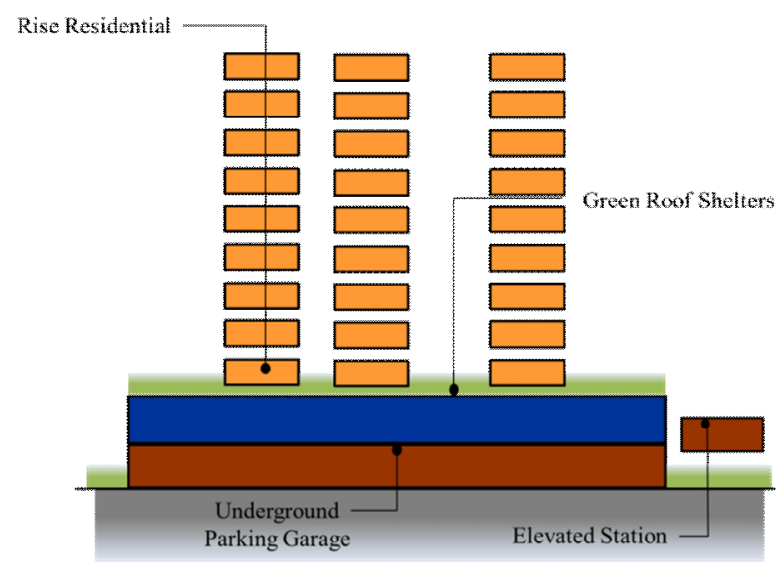

Advantages :

Figure 3. Sketch Map for the Carpet Model

I. Close combination between the elevated station and the exploitation of the upper space.

II.The thorough isolation of the working space of the depots from the superstructure for convenient management.

III. The depots is located on the ground for convenient organization of cargo transportation flow.

IV. The structure system of depots is located on the ground for easy construction.

Disadvantages:

I. Rigid utilization of the urban space and stereotyped connection between the depots and the surrounding urban space is prone to cause a sense of isolation in the upper residential areas.

II.Considering the processing demands of subway vehicles, the depots is over 1000 meters long, thus forming a huge urban block and destructing the normal urban transportation and space scale.

III. At the meantime, there are many turnouts in the throat area of the depots. Therefore, the requirements for sight demands the open design.

\section{Scope of Application:}

This model is mainly applied to the mountainous regions and hills as well as places with poor tolerance to the change of terrain height difference, such as Chongqing and Hong Kong.

\section{(2) Underground Model}

To avoid its negative impact on the urban space and traffic, such development model suggests that the major large-scale plants of the subway depots and comprehensive base should be built underground with the assistance offices accommodating the staff built above-ground. On the ground, the left urban space is replaced to form an urban form consistent with the surrounding environment according to the different demands and the corresponding building function.

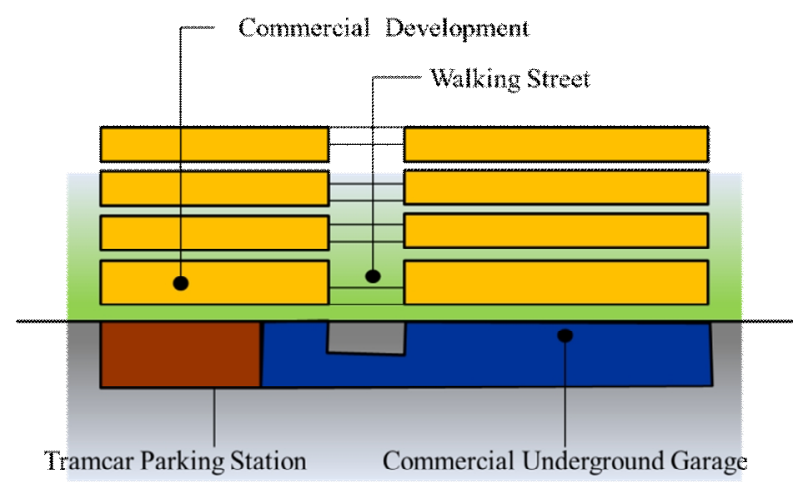

Figure 4. The Sketch Map for the Underground Model

\section{Advantages :}

I. Make full use of the underground space.

II.Use the underground rail to reduce the gradient alignment of entrance and exit section line and avoid the U-cutting on the ground.

III. Ensure the production technique and reserve the scale and context of the original urban space. 


\section{Disadvantages:}

I. It has strict requirements for geographic conditions.

II.With poor natural lighting and ventilation conditions in the car depots, the operation model will be restrained due to the spatial limitations.

III. It brings inconvenience to the surrounding municipal pipeline laying; therefore, it is of great importance to take into account the underground fire suppression and emergency plans.

\section{Scope of Application:}

It is mainly applied to the depotss in the core areas of cities, such as Guangqiu Depots in Japan and the Depots in White City.

(3) Elevated Model

As the result of the intensity in utilization of land, the conditions of entrance and exit section line fails to meet the requirement of slope of rail in the process of connecting the depots with elevated railroad; therefore, the model for the construction of elevated depots is adopted. If the depots and comprehensive base is $10 \mathrm{~m}$ higher above the ground, it is possible to set up a large number of commercial and living supporting facilities beneath the stabling yard and residence, serviced apartment and other residential buildings above the stabling yard. The adjacent elevated subway stations provide convenient transportation for property development and the property forms, such as commerce and residence also bring steady source of passengers for the terminal station. Meanwhile, other means of transportation will be organized around the elevated subway station for the purpose of establishing an improved connection transportation system.

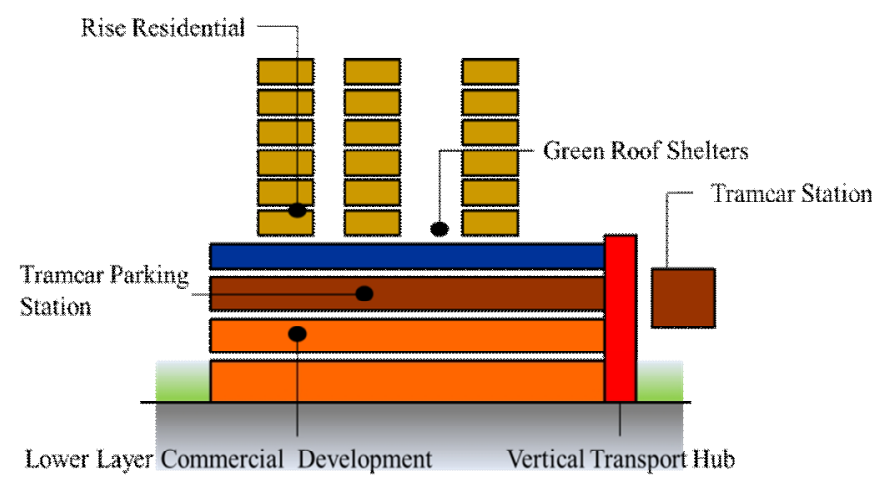

\section{Advantages :}

Figure 5. The Sketch Map for the Elevated Model

I. Overcome the influence of carpet model on urban ground transportation.

II.Avoid the high cost of underground model, ensure the natural ventilation and lighting of car depots and comprehensive base and optimize the working environment.

III. Utilize the space below for commercial development and return the floor space with the strongest accessibility to cities.

IV. Form the seamless transportation connection and the high-density commercial development through combining the adjacent stations.

\section{Disadvantages:}

I. It will bring substantial influence to the urban spatial form and scale.

II.An urban space with poor lighting conditions will be formed under the elevated throat area; for this reason, it is difficult for the landscape planting to survive and calls for the arrangement of the corresponding municipal means of transportation.

\section{Scope of Application:}

It is mainly applied to the small-scale depots, such as the stabling yard of the university town in Nanjing.

\section{Conclusions}

On the basis of the practical design experience of Huandao Depots in Foshan and Tongan Depots in Suzhou and the operational experience of Dayangshan Depots in Suzhou, this paper offer an analysis of the land-saving measures for tramcar depots with the conclusion listed as follows: 
(1) The layout and scale of the tramcar depots should be taken into account on the basis of the regional tramcar network planning so as to fully share the vehicle maintenance resources and reduce the total land area of network depots.

(2) Under limited land conditions, the measure of large-scale combination of the workshops with similar property is adopted to optimize the general layout of the car depots and comprehensive base and reduce the land area of the single-line depots.

(3) Under the premise of meeting the functions of depots, the property development at the depots and the project connecting the depots and other urban planning facilities could enhance the per area land utilization rate and realize the comprehensive land utilization.

\section{REFERENCES}

[1] Zhang Xiong. Design features of general layout for subway car depots and its optimization[J]. Journal of railway engineering society, 1999,3 (63): 91-94.

[2] Xu Jiuyong. Discussion on the General Layout of Stub-end Type Subway Depots[J]. Journal of railway engineering society, 2014,6 (189): 93-98.

[3] Liang Guangshen. Discussion on the Construction of Cost-effictive Subway Depots[J]. Urban Repid Rail Transit, 2009(12):14-17.

[4] China Railway Siyuan Survey and Design Group Co. , Ltd. Railway Engineering Design Technical Manual-railway Station and Yard[K]. Beijing: China Railway Publishing Company, 2009.

[5] Shang Yangbo, Ye Xiafei. Comparison of Depots Scale between Domestic and Foreign Urban Rail Transit Systems[J]. Urban Repid Rail Transit, 2009(3):17-19.

[6] Miao Dong. Discussion on Allocation Scale and Construction Way of Car Depots for Urban Mass Transit. Journal of railway engineering society, 2005,3 (87): 35-38. 